Lisólette Schwarzenberg de Delhey

\title{
Tipos $y$ personajes en el paisaje literario de Mariano Latorre
}

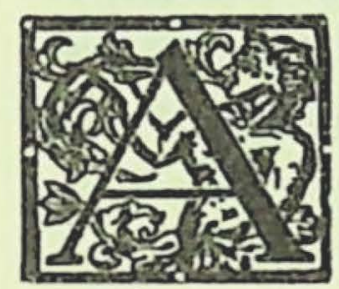

L estudiar los personajes en la obra de Mariano Latorre, hemos de hacer, en primer lugar, una distinción fundamental entre los que pueblan sus cuentos cordilleranos y campesinos y aquellos otros que son protagonistas de sus novelas urbanas.

En los cuentos del campo chileno - que son los más en la obra de nuestro autor- el hombre forma parte de la grandiosa y omnipotente naturaleza. Es un ser insignificante, sin fuerzas, que se debate inútilmente en su lucha contra los elementos y que nunca podrá dominar al medio. El hombre, como alguien ha dicho, se empequeñece ante la naturaleza y reacciona ante su ambiente con los mismos instintos que los animales. A veces, no es más que un árbol o una piedra y aun resulta difícil distinguirlo de ellos, porque físicamente ha adquirido la apariencia de un "trozo de chonta botado en el camino", como literalmente describe Mariano Latorre a una de sus hombres cordilleranos (véase Cuna de cóndores, "La cordillera sagrada", 4. ${ }^{a}$ edición, 1949, Editorial Nascimento, Santiago, páginas 185-186). Así, según afirman muchos críticos, el verdadero protagonista de estos cuentos pasa a ser la naturaleza misma. El hombre no tiene ninguna importancia. 
Así parece. Sin embargo, nadie como Mariano Latorre ha pintado a estos seres que viven perdidos en la inmensidad de la cordillera y nadie como él ha comprendido su psicología. Ante todo, hemos de recalcar que los críticos de Mariano Latorre en su mayoría sólo han visto en su obra la predominancia de la descripción de la naturaleza chilena. En cambio, no se ha reconocido hasta hoy, con el énfasis necesario, que Latorre, precisamente por haber colocado a sus personajes dentro del medio natural en que viven, nos ha dejado una obra que posee alto valor sociológico, fuera del literario, porque ha pintado tipos chilenos - más que personajes- como existen en nuestra realidad.

Las novelas urbanas hacen desaparecer casi por completo la descripción del medio para realzar la pintura psicológica de los personajes. Esta parte de la obra de Latorre, sin embargo, no constituye ni lo más típico ni lo más bello de su creación literaria. Por tal motivo, hemos de ocuparnos aquí únicamente de los personajes que aparecen en sus cuentos y novelas rurales.

En Chile, como en toda América, el hombre es un producto de la naturaleza, a diferencia del continente europeo, en donde la naturaleza está dominada por el ser humano y adquiere la forma que él le da. Mariano Latorre lo ha comprendido. En sus cuentos del campo y de los cerros, aparecen tipos humanos que no pueden existir nada más que en América y, particularmente, en Chile. Son seres que han perdido, por así decirlo, algo de su condición humana, porque se identifican en tal forma con su medio natural, que ya casi no se distinguen de él. La vista poco adiestrada del hombre de la ciudad no percibe muchas veces al serrano sentado en una piedra, a orillas del camino, porque no parece sino un tronco o un terrón de greda. Son hombres de color pardo, porque su piel está curtida por el sol y el polvo y sus harapos ya no tienen color definible. Sus ojos no brillan, porque el sol los tiene habituados a un eterno pestañear. 
Además, desde chicos han aprendido a mirar con disimulo. Los dientes, blancos en un tiempo, se han teñido con el tabaco y la alimentación incompleta. Por fin, se han caído, totalmente carcomidos. El cabello, negro y brillante por naturaleza, ha perdido su brillo de azabache, porque el sol y el polvo lo han descolorado. Además, se oculta bajo un sombrero de color indeciso: gris pardo. Sus manos parecen haces de ramas secas, o bien, se confunden con las riendas de cuero con que manejan el caballo. En suma, estos hombres se han acercado en tal forma a la naturaleza, que ellos mismos han pasado a ser naturaleza, un poco de tierra con formas humanas. Ya no son hombres, sino un trozo de paisaje. Sus sentimientos y pensamientos nunca han podido desarrollarse y han quedado reducidos a unos pocos instintos, casi todos primarios, que los colocan casi a una misma altura con los animales. Así se comprende también la estrecha relación de convivencia entre hombres y animales, como nos la describe Latorre. El cuento "Carboneros" brinda el mejor ejemplo, en que Latorre dice de On Polo y su perro:

"On Polo era hijo de los cerros, pero hacía muchos años que sus últimos parientes habían muerto. Vivió en las cocinas de los ranchos, donde le confiaban pequeños trabajos, pagados con un plato de porotos y un trozo de galleta morena que él compartía con su único amigo, un perro de campo, de larga cola, indefinible color y flacura inverosímil. Expulsado como él de todas partes, un día el azar los reunió y ya no volvieron a separarse. A fuerza de vivir juntos, se habían compenetrado. Algo del carácter del amo había pasado al perro, si podemos llamar carácter a la media docena de instintos que aún podían incluirlo entre los humanos. El perro había tomado los defectos del amo: el mal humor, el egoísmo primitivo y el hombre, las cualidades del perro: la fidelidad resignada, la indiferencia ante la miseria... Al perro colgábanle unos pelos grises de las mandíbulas, parecidos a las raleadas barbas de On Polo; pero la mayor similitud residía en los ojos, unos ojos opacos, desconfiados sin el brillo de la vida, ojos que no sabían mirar o que lo habían olvidado... On Polo parecía haber perdido el uso de la palabra y era éste 
otro lazo de unión, porque el perro, a su vez, no ladraba... Ni siquiera se supo que su amo lo llamara alguna vez y no era necesario. Algo misterioso los unía. Si el viejo daba unos pasos o se detenía, el perro hacía un movimiento equivalente". (Hombres y zorros, 2. edición. Ed. Nascimento. Santiago de Chile, 1954, páginas 52-53).

Los móviles más importantes que hacen actuar a estos personajes son, fuera de los instintos que sirven a la conservación de la vida, la astucia y el orgullo personal. Aquélla es absolutamente necesaria para apoderarse del bien ajeno y este último, absolutamente indispensable para vivir. Así, la astucia se convierte en una cualidad intrínseca del hombre serrano, una cualidad que también le acerca a un animal: al zorro de la Cordillera de la Costa (Hombres y zorros).

El orgullo personal es un sentimiento sumamente desarrollado en estos hombres primitivos y Mariano Latorre nos lo ha descrito no una, sino muchas veces. El sentimiento del honor es en ellos algo muy especial y muy susceptible. Por un quítame de ahí esas pajas, se sienten ofendidos e impelidos a la venganza, una venganza que casi siempre resulta sangrienta, porque el hombre, ofuscado por la ira, atribuye a la ofensa mayor gravedad de la que realmente tiene. Llega a un estado de verdadero paroxismo, acentuado aún por el alcohol que en estos casos suele ingerir, y termina por aniquilar al adversario en un acto de asesino irresponsable. Recordemos aquí nuevamente a On Polo que mata a palos al carbonero, porque éste le ha matado, a su vez, a su perro. Un caso análogo aparece en el cuento "¿Quién la maneó?" (Mapu, Editorial Orbe, Santiago 1942); otro, en Zurzulita (5.a edición, Ed. Nascimento. Santiago, 1952), y otro, en "Risquera vana” (Cuna de cóndores).

Una vez cometido el delito, el hombre acepta sus consecuencias, a pesar de no haberlas considerado en ningún momento antes de actuar. Las reconoce inmediatamente después de haber realizado su venganza y sabe que ahora es un individuo perseguido por la justicia, que ha de vivir al margen de la vida, siempre preparado para morir de un instante a otro. Estas consecuencias lógicas no sólo las acepta, sino que carga con ellas con una naturalidad pasmosa, tal 
como se doblega a los golpes que le asesta un destino ajeno a su voluntad. También el propio crimen es, en cierto modo, una desgracia que ha caído sobre él como una catástrofe natural. No comenta su acto criminal ni sigue cavilando mucho sobre él, ya que sus principios éticos son diferentes en todo punto a los de un europeo, por ejemplo.

A pesar de todo, esta solución de estoicismo resulta consoladora ante la compacta y trágica realidad. Este hombre del pueblo, estoico, pero también cristiano sincero, no se rebela contra su destino. Al morir una persona querida, por ejemplo, los allegados acompañan a los deudos y los saludan: — "Dios lo ha querido así, El nos dará la conformidad”. La humildad, la aceptación y el conformarse con todo constituyen la nota más sobresaliente en su psicología.

No hemos de olvidar que estas últimas características son, en grado mayor o menor, comunes a los campesinos de toda la tierra. Dentro de su medio, están a salvo de las rebeldías del alma que pudieran sublevarlos contra el destino. En cambio, pierden la seguridad de sí mismos, al abandonar el campo e irse a la ciudad. Allí, donde las cosas se miden con otra medida, desarraigados, son víctimas de todas las tentaciones y de todos los vicios. Mariano Latorre nos plantea este problema en "Sandías ribereñas" (Cuentos del Maule, Tipos y paisajes chilenos, Talleres de la Empresa Editora ZigZag, Santiago, 1912), en que la pequeña Rosario pierde su inocencia, cuando su padre la lleva al puerto. Otro ejemplo nos lo ofrece el bandido Nicomedes Román, en "Risquera vana", muchacho bueno de los cerros que, después del servicio militar, ya no vuelve al hogar y termina en la cárcel por asesino. A la luz de estas reflexiones, resulta impresionante que Latorre haga perder al bandido toda la petulancia -ficticia seguridad de sí mismo- que lo caracterizaba en la ciudad, en cuanto vuelve a encontrarse a solas con la inmensidad de la cordillera de los Andes. En ese momento, se convierte nuevamente en el pequeño ser indefenso que vive dominado por la naturaleza. 
Entre los tipos más sobresalientes que nos pinta Mariano Latorre, está el huaso chileno. Basta con recorrer las páginas de cualquiera de sus libros, para encontrarse con el retrato patente de este personaje popular de nuestro país. Además, es interesante la comparación que hace Latorre, en repetidas oportunidades, entre el huaso y el gaucho argentino. En las mismas páginas de esta revista ("El huaso y el gaucho en la poesía popular", "Atenea", año XIII, tomo XXXVI, N. ${ }^{\circ} 138$ ), nuestro autor se ha expresado acerca de este tema, de modo que no seremos nosotros quienes repitamos sus propias palabras. Sin embargo, vale mencionar aquí sus cuentos "El triunfo del chey" (Cuna de cóndores) y "Si es hombre, patrón..." (Viento de Mallines, 2. ${ }^{\text {a }}$ edición, Empresa Editoria Zig-Zag, Santiago, 1947).

Otros tipos chilenos que Mariano Latorre nos presenta, o mejor, que presenta a sus lectores de otros países, son: el roto (Taquilla, Juan Sapo de Hombres y zorros; on Polo, Nicomedes Román, de Cuna de cóndores; Ambrosio Muñoz de Viento de Mallines, etc.), el mediopelo ("El finado Valdés", de Puerto Mayor y Chilenos del mar, Empresa Editora Zig-Zag, 1945; Teresita Cecchi y su esposo, de Collares, "Lectura Selecta", revista semanal de novelas cortas, Santiago de Chile, año II, N. 51, 2 de septiembre de 1927, editada por José S. Gallay), el futre ("Santiaguinos en el mar", de Pucrto Mayor y Chilenos del mar), el siútico (Ruiz Tagle de La confesión de Tognina, "Lectura Selecta", Santiago, año I, N. ${ }^{\circ} 1,10^{\circ}$ de enero de 1926), y el indio mapuche (Mapu). Además, se detiene con amor en los relatos de guanayes maulinos (Cuentos del Maule, Puerto Mayor y Chilenos del mar) - son sus compatriotas más cercanos- y de chilotes (Chilenos del mar), por ser los marinos de Chile. Si hubiese tenido tiempo, Latorre también nos habría descrito al obrero de las minas del norte y al gaucho de las estancias ovejeras de Magallanes. Pero la vida no le alcanzó para abarcar en su obra todos los ámbitos de Chile.

Hemos de prestar especial atención a las mujeres y a los niños que aparecen en los cuentos y novelas de Mariano Latorre. 
En el cuento "Risquera vana", ya varias veces mencionado, aparece un tipo perfecto de "china", representado por la niña Florinda. En la descripción de esta mujer, ha vertido Mariano Latorre toda su sabiduría y toda la penetración psicológica que lo caracterizan. Tal como en la vida del hombre, también en la de la mujer del pueblo chileno, son los factores exteriores los que determinan su suerte. A veces, cuando jóvenes, un destino bondadoso las lleva hacia un hombre honrado que les conserva su cariño y permanece por toda la vida a su lado. Pero no es esto lo más común. Por el contrario, y Florinda es el caso más típico de la mujer que, impelida por su amor hacia el primer hombre que ha conocido en su vida, se entrega confiada a él, desoyendo las advertencias de su madre que le dice: "-Cuidado, Florinda, los guainas son como risqueras vanas, por juera parece que no hubiera ná y aentro hay escondío un zorro" (Cuna de cóndores, ed. cit., página 46). No dura el cariño del hombre. Nicomedes la abandona al clarear el alba en la inmensidad de la cordillera y sigue solo su camino hacia la pampa argentina. Cuando Florinda despierta en la cueva que les ha servido de refugio, nota la ausencia del mozo e inmediatamente se da cuenta de que ha sido burlada. Como todos los tipos serranos de Latorre y de Chile, su aflicción es pasiva y la conformidad no se deja esperar. Lo único que dice es: - “ $\mathrm{iNi}$ siquiera me dejó un piacito e pan!" (obra, cit. página 58). Luego vuelve a ensillar su caballo y emprende el camino de vuelta, ya resignada, como si fuera la cosa más natural del mundo. Su madre es un verdadero compendio de sabiduría, porque no la recibe sino con unas palabras muy calmadas, también como si fuera la cosa más natural del mundo: “- ¿Ya llegaste, niña?" Y luego: —“¿No vis? ¿No te icía yo que los guainas son como risqueras vanas?” (obra cit. página 59).

Lo mismo que a Florinda, les sucede a muchas otras, no sólo en la obra de Mariano Latorre (Rosarito, de "Sandías ribereñas"; Uberlinda Farías de "El angelito" Sus mejores cuentos, 2.a edición, Ed. Nascimento, Santiago, 1945; Milla, de Zurzulita), sino en la vida real de Chile. Es el problema de la madre soltera. 
Pero también están las otras, las que no son solteras, sino casadas, pero casi nunca felices. Veamos, por ejemplo, el cuento "Domingo Persona" (Hombres y zorros). En este relato, Mariano Latorre narra un episodio de la vida del matrimonio Basoalto. Nicomedes Basoalto es un tirano, un déspota. Su mujer, Luzmira, es su esposa y la madre de sus hijos, que van aumentando de año en año. Pero el hombre no la trata sino como a una esclava, le habla golpeado, en forma autoritaria y nunca tiene consideraciones o cuidados para con ella. Es más, la mortifica con sus celos ya sin fundamento, porque en los años de casada, Luzmira se ha transformado en una mujer ajada que ha perdido sus atractivos de niña. Todo esto podría inducir a pensar que una mujer tan desgraciada terminará algún día por dejar al marido. Pero no, la mujer chilena es la más fiel y consciente de sus deberes y nunca ha de abandonar a sus hijos ni al esposo, por muy malo que éste sea. Muchas veces es ella quien mantiene el hogar con el trabajo de sus propias manos, porque el hombre bebedor no le da el dinero indispensable para pagar el sustento (véase Teresita Cecchi, de Collares). El hombre, sin embargo, jamás ha de darle una sola palabra de gratitud en recompensa. Así sucede en el caso de Nicomedes y Luzmira Basoalto.

Una mujer interesante desde el punto de vista psicológico es Milla, la zurzulita de Mateo Elorduy (Zurzulita). Fresca, limpia, apetitosa y un poco esquiva cuando niña, sufre una metamorfosis completa después de su unión carnal con Mateo. Es entonces una mujer madura y cariñosa, dicho brevemente: muy femenina. Pero cuando va a ser madre y Mateo le propone matrimonio, lo rechaza con una dureza incré́ble. Esta actitud suya, tan negativa y tan poco esperada, no convence del todo al lector.

Quienes más nos emocionan en la obra de Latorre, son los niños. Ocupan en ella un lugar muy destacado. Son los niños pobres del campo y de la cordillera que se han ganado el corazón de nuestro poeta y que nos emocionan profundamente a través de sus narraciones. Allí tenemos al pequeño Moñi (Cuna de cóndores), quien, por salvar a los terneritos recién nacidos de su rebaño, se traba en 
épica lucha con un cóndor y, como sus escasas fuerzas no alcanzan para dominar al enorme ave de rapiña, perece en mortal abrazo con clla. Allí están también Llolli y Cachuzo (Cuna de cóndores), dos mellizos que viven en la montaña y que exteriormente parecen ser iguales; pero que en el fondo se odian, porque ambos tratan de ganarse el cariño del padre severo; por fin, el más débil de los dos, es despeñado por el otro y se encuentra solo y abandonado en la inhóspita cordillera. No olvidemos a la pequeña Rosario de "Sandías ribereñas" (Cuentos del Maule), la niñita inocente y un poco esquiva, que pierde la pureza de sus sentimientos en cuanto su padre la lleva al puerto y la deja a merced de una vieja celestina. Alguien más: Quicho, el hermano de Milla (Zurzulita), única amigo de Mateo Elorduy, cuando este último se va a vivir al campo, aunque no ha nacido para ello. Por último, hay todos esos niños indios que Latorre nos ha presentado en su libro Mapu y aquellos otros que aparecen en sus cuentos infantiles "El choroy de oro" y "Trapito sucio" (Editorial Rapa-Nui, S. A., Santiago, 1946). Todos ellos son niños de carne y hueso, niños tan vivos como los que vemos día a día por las calles y en los campos, niños que nos miran con sus ojos grandes y cuya mirada sabe ya de la miseria, del hambre y del frío. Son niños, cuyos destinos, narrados por Latorre, nos atañen personalmente y cuyas penas y alegrías compartimos de todo corazón.

¿Qué particularidad tienen estos niños, que los hace aparecer tan distintos a todos los demás que pueblan la literatura del mundo? En primer lugar, llama la atención el que estos niños chilenos de Latorre sean tan precoces y se enfrenten con la vida en una actitud de seria responsabilidad. $\mathrm{Y}$ es así en realidad. Si vamos al campo, nos asombra ver que esos niños, a los cuatro años de edad, son ya pequeños adultos que saben muchas cosas, trabajan y responden a las preguntas que les hagan, con una seriedad absoluta, algo inverosímil en proporción a su diminuto cuerpecito. En la ciudad, es otra cosa. Allí, los niños crecen en el seno de sus familias, protegidos y mimados, hastiados de juguetes, casi siempre egoístas y malcriados. Son los niños regalones, acostumbrados a que se cumplan todos y 
cada uno de sus deseos, niños exigentes que, sin embargo, nunca se contentan con nada. Estos niños no tienen carácter, o mejor, no lo han desarrollado todavía, pero en ningún caso lo tienen para Mariano Latorre, quien ha conocido a esos otros niños, los pobres, los que viven en el campo y la cordillera, los que cuidan los rebaños, van al campo a buscar los animales y dan aviso oportuno cuando notan la falta de alguno de ellos; niños que conocen a cada animal del rebaño, por muy numeroso que sea, y cuya vista, a igual que la vista del padre vaquero, percibe y distingue cualquier cambio; niños que viven tan usidos con las cosas de la naturaleza, que han desarrollado un sexto sentido para percatarse de cualquier peligro, aún cuando éste se encuentre muy lejos; niños que saben de inmediato, cómo deben conducirse al aparecer en la inmensidad del cielo azul un puntito negro, un cóndor, que amenaza a los tiernos animalitos recién nacidos; niños, en fin, que ya no juegan, sino que trabajan como adultos y se enfrentan a la vida absolutamente responsables ante sí mismos. Estos niños han nacido en la naturaleza, viven de ella, con ella y para ella y casi han dejado de ser hijos del hombre para transformarse en hijos de esa misma naturaleza. Tal como el hombre de la montaña, estos niños se parecen a la tierra, tienen el mismo color de los troncos y de las piedras y se mueven con la agilidad de los animales serranos. Esta fusión de naturaleza y hombre no sería posible, por lo demás, si no comenzase ya en los niños para transmitirse de generación a generación.

Estos seres viven solitarios, separados por grandes distancias los unos de los otros, y sólo muy a la larga van al pueblo o al caserío más cercano para comprar hierba y azúcar en la pulpería. A veces, arrean manadas de vacunos a la cordillera, a la Argentina, o vuelven con animales comprados en la Pampa a Chile. Siempre son pocas las oportunidades en que alternan con sus semejantes. Si hablan, lo hacen con parquedad. Sus compañeros son los animales, vacunos, cabras u ovejas, casi siempre un caballo y un perro. Así, se transforman en seres callados, tímidos y hasta desconfiados, como los propios animales. 